\title{
Differential effects of cocaine and MDMA self-administration on cortical serotonin transporter availability in monkeys
}

\author{
Robert W Gould, B.S. ${ }^{a}$, H Donald Gage, Ph.D. ${ }^{b}$, Matthew L. Banks, PharmD, PhD. ${ }^{a, 1}$, Brandi \\ L Blaylock, B.S. ${ }^{a}$, Paul W Czoty, Ph.D. ${ }^{a}$, and Michael A Nader, Ph.D. ${ }^{a},{ }^{,}{ }^{*}$ \\ Robert W Gould: rgould@wfubmc.edu; H Donald Gage: dgage@wfubmc.edu; Brandi L Blaylock: bblayloc@wfubmc.edu; \\ Paul W Czoty: pczoty@wfubmc.edu \\ a Department of Physiology and Pharmacology, Wake Forest University School of Medicine, \\ Winston-Salem, NC 27157 \\ b Department of Biomedical Engineering, Wake Forest University School of Medicine, Winston- \\ Salem, NC 27157 \\ c Department of Radiology, Wake Forest University School of Medicine, Winston-Salem, NC \\ 27157
}

\section{Abstract}

Cocaine self-administration alters brain dopaminergic and serotonergic function primarily in mesolimbic and prefrontal brain regions whereas 3,4-methylenedioxymethamphetamine (MDMA) self-administration predominately alters brain serotonergic function in a more widespread distribution across cortical regions. We previously reported that, compared to drug-naïve rhesus monkeys, self-administration of cocaine but not MDMA was associated with increased serotonin transporter (SERT) availability in two mesolimbic regions, the caudate nucleus and putamen, as measured by positron emission tomography (PET) using the SERT-specific ligand $\left[{ }^{11} \mathrm{C}\right]-3$ amino-4(2-dimethylamino-methyl-phenylsulfanyl)-benzonitrile $\left(\left[{ }^{11} \mathrm{C}\right] \mathrm{DASB}\right)$. The goal of the present study was to extend this comparison between cocaine and MDMA self-administration to SERT availability in cortical regions, which have been shown previously to be affected in human drug abusers and are associated with executive function. PET studies using $\left[{ }^{11} \mathrm{C}\right] \mathrm{DASB}$ were conducted in adult male rhesus monkeys with a history of cocaine (mean intake $=742.6 \mathrm{mg} / \mathrm{kg}$ ) or MDMA (mean intake $=121.0 \mathrm{mg} / \mathrm{kg}$ ) self-administration, and drug-naïve controls ( $\mathrm{n}=4 /$ group). Regions of interest were drawn for several cortical (prefrontal, temporal, parietal, occipital and midcingulate) and subcortical (thalamus, amygdala and hippocampus) areas. Cortical SERT availability was significantly higher in monkeys with a cocaine self-administration history compared to controls whereas MDMA self-administration resulted in lower levels of SERT availability. These data extend our previous findings indicating that cocaine and MDMA selfadministration differentially alter SERT availability in subcortical and cortical regions, which may have implications for development of treatment drugs.

(C) 2011 Elsevier Ltd. All rights reserved.

*Corresponding author: Michael A. Nader, Ph.D., Department of Physiology \& Pharmacology, Wake Forest University School of Medicine, Medical Center Blvd., 546 NRC, Winston-Salem, NC 27157-1083, PH: 336-713-7172, FAX: 336-713-7180, mnader@wfubmc.edu.

${ }^{1}$ Current address: Department of Pharmacology and Toxicology, Virginia Commonwealth University, 410 N 12th St, Robert Blackwell Smith Bldg, Rm 640, PO Box 980613 Richmond, VA 23298 mbanks7@vcu.edu

Publisher's Disclaimer: This is a PDF file of an unedited manuscript that has been accepted for publication. As a service to our customers we are providing this early version of the manuscript. The manuscript will undergo copyediting, typesetting, and review of the resulting proof before it is published in its final citable form. Please note that during the production process errors may be discovered which could affect the content, and all legal disclaimers that apply to the journal pertain. 


\section{Keywords}

MDMA; cocaine; self-administration; nonhuman primates; PET; SERT

\section{INTRODUCTION}

Cocaine and 3,4-methylenedioxymethamphetamine (MDMA) are abused psychostimulants that have affinity for dopamine (DA), serotonin (5-HT), and norepinephrine (NE) transporters (DAT, SERT, and NET, respectively). Whereas cocaine has similar affinities at DAT, SERT and NET (Bennett et al., 1995), MDMA has 10-fold higher affinity at SERT compared to DAT (Steele et al., 1987; Battaglia et al., 1988), perhaps explaining the lower rate of acquisition (Schenk et al., 2007) and the weaker reinforcing strength of MDMA compared to cocaine (Lile et al., 2005). Consistent with its high affinity and selectivity for SERT, MDMA exposure has been associated with alterations in the 5-HT system (for reviews see Sprague et al., 1998; Green et al., 2003; Gudelsky and Yamamoto, 2008; Schenk, 2009; Sarkar and Schmued, 2010). In vitro examination following MDMA administration showed lower binding in 5-HT uptake sites but not DA or NE uptake sites measured via in vitro receptor autoradiography (e.g., Battaglia et al., 1987, 1988, 1991; Insel et al., 1989; Scanzello et al., 1993; Schenk et al., 2007; Biezonski and Meyer, 2010) as well as SERT internalization (Kittler et al., 2010; Kivell et al., 2010) compared to cocaineinduced elevations in membranous SERT expression (Kittler et al., 2010). In vivo examination assessed via PET imaging showed MDMA associated reductions in SERT availability in rodents (Li et al., 2010), nonhuman primates (Scheffel et al., 1998; Szabo et al., 2002), and human MDMA abusers compared to control subjects (Buchert et al., 2003, 2004, 2006, 2007; McCann et al., 1998, 2005, 2008; Kish et al., 2010), but no alterations in DAT availability in monkeys (Fantegrossi et al., 2009) or humans (McCann et al., 2008). In contrast, cocaine exposure was associated with elevated SERT availability (Mash et al., 2000; Banks et al., 2008) and DAT binding in monkeys (Letchworth et al., 2001) and humans (Little et al., 1993).

Although chronic cocaine and MDMA exposure are both associated with impairments in memory, other cognitive domains are differentially affected. For example, cocaine exposure in humans is predominately associated with increased perseverative responding and deficits in response inhibition (Fillmore and Rush, 2002; Kaufman et al., 2003; Hester and Garavan, 2004; Ersche et al., 2008; Colzato et al., 2009; Turner et al., 2009). Recent fMRI studies have associated deficits in performance with hypoactivation within PFC brain regions (Kaufman et al., 2003; Hester and Garavan, 2004; Kubler et al., 2005; Goldstein et al., 2007) which are hypothesized to perpetuate compulsive drug seeking (Volkow and Fowler, 2000; Goldstein and Volkow, 2002; Everitt and Robbins, 2005). In contrast to cocaine, MDMA exposure affects mnemonic processes including spatial, working and episodic memory domains without affecting simpler aspects such as vigilance, reaction time, and selective attention, and response inhibition (Parrot and Lasky, 1998; Parrot et al., 1998; Vollenweider et al., 1998; Roberts and Garvan, 2010). In fact, using an identical task, recreational MDMA users showed hyperactivity in the ACC as measured via fMRI and performance on a response inhibition test was not different from controls (Roberts and Garavan, 2010) whereas cocaine users showed distinct ACC hypoactivity and impaired performance (Kaufman et al., 2003). Single low doses of MDMA have produced cognitive impairments lasting up to 72 hours post-administration (Verrico et al., 2008), whereas acute low doses of cocaine produced cognitive enhancement (e.g., Fillmore et al., 2005, 2006; for a review of cognitive implications of single and polydrug use, see Fernandez-Serrano et al., 2010). While cognition is not assessed in the current study, region-specific differences in monoaminergic brain function may account for differential cognitive impairments between 
cocaine and MDMA users. Therefore, development of effective treatment strategies for cocaine and MDMA abuse will be aided by a better understanding of the neurobiology associated with MDMA and cocaine self-administration that may underlie specific cognitive and behavioral effects associated with each drug.

Laboratory animal studies have been used to better understand how drugs alter brain function without polydrug use and other potentially confounding factors inherent in research with humans. In a recent study using the SERT-specific PET ligand $\left[{ }^{11} \mathrm{C}\right]-3$-amino-4(2dimethylamino-methyl-phenylsulfanyl)-benzonitrile $\left(\left[{ }^{11} \mathrm{C}\right] \mathrm{DASB}\right)$, we reported that rhesus monkeys with a history of cocaine self-administration had significantly higher SERT availability in two striatal regions, the caudate nucleus and the putamen, compared to monkeys with a history of MDMA self-administration; the latter group was not different from control animals (Banks et al., 2008). The aim of the present study was to reanalyze those PET data in order to extend previous findings to cortical regions associated with cognitive performance and to directly compare the effects of cocaine and MDMA on SERT availability in regions shown to be affected in human drug abusers. We hypothesized that, compared to drug-naïve monkeys, SERT availability would be lower in cortical regions of monkeys with an MDMA self-administration history and higher in monkeys with a history of cocaine self-administration.

\section{MATERIALS AND METHODS}

\subsection{Subjects}

Twelve adult male rhesus monkeys (Macaca mulatta) served as subjects. Four monkeys self-administered MDMA daily, four self-administered cocaine daily and four were drugnaïve. At the time of the PET studies, the range of lifetime drug intake was $97-141 \mathrm{mg} / \mathrm{kg}$ for MDMA-exposed monkeys and 537-1029 mg/ $\mathrm{kg}$ for cocaine-exposed animals (for more detailed information see Banks et al., 2008). Of note, the MDMA group also had a limited, prior history of cocaine self-administration $(<120 \mathrm{mg} / \mathrm{kg}$ cumulative intake; $~ 5-10$ times less than the current cocaine self-administration group) but at the time of the PET studies, the primary drug of study (cocaine or MDMA) had been exclusively available for 10-12 months (see Banks et al., 2008, Table 1). All monkeys were weighed regularly, fed enough food daily (LabDiet Monkey Chow and fruit supplementation) to maintain body weights at approximately $95 \%$ free feeding weights and had water available ad libitum in the homecage. All procedures were approved by the Wake Forest University Animal Care and Use Committee.

\subsection{PET Imaging}

T1-weighted magnetic resonance images (MRIs) using a 1.5-Tesla GE Signa NR scanner (GE Medical Systems) were acquired from each monkey several weeks before the PET study and were used for co-registration purposes with PET images to confirm placement of regions of interests (ROIs) (see below). On the day of the PET study ( 24 hours after the last self-administration session), monkeys were anesthetized with $8.0 \mathrm{mg} / \mathrm{kg}$ ketamine and transported to the PET Center; anesthesia was maintained via 1.5\% inhaled isoflurane for the duration of the 90-minute scan. A 22-ga catheter was placed into an external vein by percutaneous stick for intravenous administration of $\left[{ }^{11} \mathrm{C}\right] \mathrm{DASB}$ as described previously (Banks et al., 2008). PET imaging was conducted on a GE Advance NXi PET Scanner (GE Systems, Milwaukee, WI) with approximately 4-mm resolution (see Banks et al., 2008). Data analysis was conducted using PMOD Biomedical Image Quantification Software (version 3.1; PMOD Technologies, Zurich, Switzerland). Distribution volume ratios (DVRs) were calculated by implementing the "Logan method" of analysis in PMOD (Logan et al., 1996) using the posterior-lateral aspect of the cerebellum as our reference region. Although 
SERT is present in the cerebellum, there is comparatively lower distribution of SERT in the posterior-lateral regions compared to the cerebellar vermis (Elfving et al., 2007) and is typically used as a reference tissue for [ ${ }^{11}$ C]DASB PET analysis (e.g., McCann et al., 1998, 2005, 2008; Buchert 2003, 2006).

\subsection{Regions of Interest}

Cortical regions of interest were selected based on previous studies showing MDMAassociated changes in SERT availability, (e.g., Scheffel et al., 1998; Kish et al., 2010) and a relationship between memory and SERT availability (McCann et al., 2008). Spheres were placed on PET images co-registered to each individual monkey's MRI. This technique was implemented because our cortical ROIs were large. By using overlaid PET and MR images, we included the area of highest binding within each lobe but ensured ROIs were restricted within the boundaries of each lobe. Cortical ROIs were placed on the following regions: bilateral occipital cortex (OcC, 5.0-mm radii), bilateral temporal cortex (TC, 5.0-mm radii), bilateral parietal cortex (ParC, 4.0-mm radii), unilateral prefrontal cortex (PFC, 5.0-mm radius), and unilateral midcingulate cortex ( $\mathrm{mCC}, 4.0-\mathrm{mm}$ radius). Boundaries for each ROI were as follows: OcC: primary visual cortex (V1/V2) bounded medially by the central sulcus, ventrally by the cerebellum, and rostrally by the occipito-parietal sulcus; TC: centered around the ventral aspect of the superior temporal sulcus, bordered dorsally by the insular cortex and medially by the lateral ventricle, including areas TAa, TPO, PGa, IPa, TEa and TEm; parietal cortex: including the anterior intraparietal area (AIP) and Brodmann's area 7 bounded by the intraparietal and superior temporal sulci, rostrally and caudally, respectively; dorsomedial PFC: centered on the cingulate sulcus encompassing bilateral Brodmann areas (BA) 9, 10, 24, 32 and 46 bounded caudally by, and ventrally at the level of, the corpus callosum; mCC: centered on the cingulate sulcus positioned dorsal to the caudate nucleus (drawn in the sagittal section) and $\sim 15$-mm caudal to the genu of the corpus callosum including BA 24a', $\mathrm{b}^{\prime}, \mathrm{c}^{\prime}, 32^{\prime}$ and overlapping the lower portion of the supplementary motor area (F3) (see Figure 1 for representative locations). Large PFC and mCC ROIs placed along the midline eliminated the need for bilateral ROIs. Cerebellar spheres (4.0-mm radii) were placed on the MRI along the ventrolateral aspects of the cerebellum.

Additional subcortical regions of interest based on known distribution of SERT or implications in cognition included thalamus, amygdala and hippocampus. Each location was determined by anatomical landmarks on the MRI. A single sphere (3.0-mm radius) was placed on the midline within the boundary of the rostral aspect of the thalamus. The thalamus diverges laterally as it progresses caudally, therefore rostral placement with a larger diameter encompassed a portion of both the left and right thalamus. The amygdalar ROIs (2.5-mm radii) were drawn on the coronal slice approximately 2-mm caudal to where the anterior commissure (AC) was no longer present; hippocampal ROIs $(2.5$-mm radii) were placed approximately $3.0 \mathrm{~mm}$ caudal to the most distal point of the amygdalar ROI. No significant differences overall, or within specific groups were apparent between DASB binding from left and right ROIs for any brain region; values were therefore averaged to yield a single measure for each region. To validate the implementation of new analytical software within our laboratory, bilateral ROIs (2.5-mm radii) were also drawn directly on each individual's MR in the caudate nucleus, putamen and rostral anterior cingulate cortex (rACC; BA 24a, b, c, 32; rostral to the anterior commisure) to compare with previously published DVRs within these regions (Banks et al., 2008). Briefly, this comparison was warranted to address the comparability between PET imaging results generated by previous methodologies (e.g., Banks et al., 2008) wherein time-activity curves were generated for each ROI and DVRs were calculated using the linear portion of the Logan plot (Logan et al., 1996) compared to the current analysis wherein the "Logan method" was automatically 
applied using PMOD software. Both methods inherently apply the same graphical approach, but justification with a new automated method was necessary for future comparison between studies. This comparison also served to examine inter-investigator reliability in ROI placement following anatomical landmarks on MR images.

\subsection{Statistical Analysis}

The primary dependent variable was the distribution volume ratio (DVR) for each region of interest. A one-way analysis of variance (ANOVA) was conducted for each region using SigmaStat graphing software. A significant effect was followed by Holm-Sidak pairwise post-hoc tests. In all cases $\mathrm{p}<0.05$ was considered statistically significant. Individual t-tests were used to compare DVRs within the $\mathrm{Cd}, \mathrm{Pt}$, and $\mathrm{rACC}$, generated via the current methods and the DVRs previously published by Banks et al. (2008), to examine any differences in analysis method or ROI placement. Further, individual ANOVAs for each region were conducted on the newly generated DVRs (identical statistical analysis as Banks et al., 2008) to see if any subtle changes in variability might influence overall effects of selfadministration histories.

\section{RESULTS}

Individual and group mean DVRs are shown in Table 1. For all groups, the largest DVRs for DASB were in the thalamus, followed by the amygdala. Comparing MDMA, cocaine and control groups, ANOVAs revealed a main effect in the PFC $\left(\mathrm{F}_{2,9}=4.510, \mathrm{p}<0.05\right), \mathrm{mCC}$ $\left(\mathrm{F}_{2,9}=73.984, \mathrm{p}<0.001\right)$, parietal cortex $\left(\mathrm{F}_{2,9}=6.136, \mathrm{p}<0.05\right)$ and occipital cortex $\left(\mathrm{F}_{2,9}=7.373, \mathrm{p}<0.05\right)$, but not in the temporal cortex (see Table 1). Post-hoc analyses indicated significantly greater SERT availability in monkeys with a history of cocaine selfadministration (Figure 2) compared to drug-naïve monkeys in the midcingulate cortex $(\mathrm{p}<0.001)$, and in the prefrontal, parietal and occipital cortices (all $\mathrm{p}<0.05)$ compared to monkeys with a history of MDMA self-administration. SERT availability was significantly lower in monkeys with a history of MDMA self-administration compared to control monkeys in the parietal $(\mathrm{p}<0.05)$ and midcingulate cortices $(\mathrm{p}<0.005)$ and approached significance in the occipital cortex $(\mathrm{p}=0.057)$. ANOVAs revealed no main effect in the thalamus, amygdala or hippocampus.

There were no differences in DVRs for the Cd, Pt and rACC within any group (control, cocaine, MDMA) between the previously published values (Banks et al., 2008) and current DVRs (data not shown). As in the previous study, ANOVAs revealed a significant main effect of self-administration history in the $\mathrm{Cd}\left(\mathrm{F}_{2,9}=7.22\right.$, $\left.\mathrm{p}<0.05\right)$, putamen $\left(\mathrm{F}_{2,9}=6.78\right.$, $\mathrm{p}<0.05)$, and $\mathrm{rACC}\left(\mathrm{F}_{2,9}=4.46, \mathrm{p}<0.05\right)$. Post $-h o c$ analyses indicated significantly greater SERT availability in monkeys with a history of cocaine self-administration than monkeys with a history of MDMA self-administration and control monkeys in the caudate nucleus and putamen $(\mathrm{p}<0.05)$. In the rACC, SERT availability was significantly greater in monkeys with a cocaine self-administration history compared to monkeys with an MDMA selfadministration history $(\mathrm{p}<0.05)$ but there were no differences between either selfadministration groups compared to the control monkeys ( $p>0.05$ ).

\section{DISCUSSION}

The aim of the present study was to extend our previous examination of the effects of cocaine and MDMA self-administration on SERT availability in rhesus monkeys from subcortical regions, implicated in the reinforcing effects of psychostimulants, to cortical regions associated with cognitive function. Previously, using these monkeys and DASB PET imaging, we reported significantly higher SERT availability in the caudate nucleus and putamen in monkeys with a history of cocaine self-administration compared to control 
monkeys (Banks et al., 2008). Examination of additional ROIs, outside of the striatum, found higher SERT availability in monkeys with a cocaine self-administration history compared to controls, which is consistent with preclinical reports showing increased SERT binding using in vitro receptor autoradiography (Cunningham et al., 1992; Mash et al., 2000) and in clinical reports using single-photon emission computerized tomography (Jacobsen et al., 2000). In contrast, monkeys with a history of MDMA self-administration showed significantly lower cortical SERT availability compared to control animals. There were several cortical regions in which SERT availability was significantly different between cocaine- and MDMA-exposed monkeys, supporting the hypothesis that the neuropharmacological consequences of chronic self-administration are different for these two drugs. Such information suggests that effective treatment strategies may differ for MDMA and cocaine abusers.

In accordance with rodent (e.g., Li et al., 2010), nonhuman primate (Scheffel et al., 1998; Szabo et al., 2002) and human PET studies (Buchert et al. 2003, 2004, 2006, 2007; McCann et al., 1998, 2005, 2008; Kish et al., 2010), monkeys with a history of MDMA selfadministration showed lower SERT availability in the midcingulate and parietal cortices, and differences that approached significance in the occipital cortex, compared to drug-naïve monkeys. Regional effects of MDMA on SERT availability are variable across species and studies. For example, Li et al., (2010) showed reductions in SERT availability in all areas examined (midbrain, thalamus, hypothalamus, hippocampus, caudate putamen, and frontal cortex) in rodents and Sheffel and colleagues (1998) showed reductions in SERT availability in baboons with the largest reductions observed in the occipital and frontal cortices and lesser, yet significant reductions in the parietal but not temporal or cingulate cortices. Kish et al. (2010) showed a rostrocaudal shift in cortical regions such that largest effects of MDMA use in humans were in the occipital cortex followed by less robust but still significant effects in the temporal, insular, parietal, cingulate and frontal cortices.

Differences across studies may be due to MDMA history, polydrug use, individual subject variability, duration of abstinence, or perhaps even data analysis methods. Related to this last point, using these same PET scans, we had previously reported no significant difference between monkeys with a history of MDMA self-administration and control monkeys in SERT availability in the rACC (Banks et al., 2008), a result that was replicated in the current analysis. However, the cingulate cortex extends the length of brain bordering the corpus callosum from genu to splenium and delineations within this structure based on function are becoming increasingly apparent. In the current analysis we examined SERT availability in what has been termed the midcingulate, an area located dorsally to the caudate nucleus and 15-mm caudal to the genu of the corpus callosum, compared to the rACC ROI located rostral to the genu of the corpus callosum in the Banks et al. (2008) study. The two distinct locations are aligned with Brodmann areas 24 and 24', as delineated by Bozkurt et al. (2005) and correspond with the anterior cingulate and midcingulate, respectively, as defined by Palomero-Gallagher et al. (2009) in human brain. Despite neurotransmitter receptor heterogeneity throughout the cingulate cortex, specific receptor distributions vary across rostro-caudal regions in both rhesus monkeys (Bozkurt et al., 2005) and humans (PalermoGallagher et al., 2009). Recent evidence supports 4 distinct cingulate cortical regions, subdivided further into 7 distinct functional domains based largely on network analysis studies using fMRI (e.g. Devinsky et al, 2005; Vogt, 2005; Yu et al., 2010). Regional differences in receptor architecture and function may explain differences in SERT availability between the present findings and the previous findings of Banks et al. (2008) and may explain apparent anomalies between clinical studies as well.

The dosage, cumulative intake, route and duration of time following last MDMA exposure prior to SERT examination may also contribute to regional differences between studies. A 
majority of studies showing alterations in 5-HT uptake binding sites or specific SERT binding in rodents and monkeys have used a 4 day, twice daily experimenter-administered dosing regimen (e.g. Battaglia et al., 1988, 1991; Insel et al., 1989; Schefel et al., 1998; Li et al., 2010). However, self-administration studies have also demonstrated MDMA-associated reductions in SERT binding (e.g., Schenk et al., 2007; for a review see Schenk, 2009). Inherently, differences in individual sensitivities to the reinforcing effects of psychostimulants will influence daily, weekly, and lifetime drug intake. The present study was designed to examine the effects of chronic MDMA or cocaine self-administration in which monkeys regulated their drug intake to more closely model the human condition. Specifically examining the DVRs from the one monkey in each group that had the greatest weekly intake of cocaine or MDMA (R-1346 and R-1361, respectively; see Banks et al., 2008 for detailed intake) does not suggest that significant group differences were a result of greater drug intake by these two monkeys. In all cases, reinforcing doses of both drugs were studied for extended periods. While it would have been ideal to match intakes between monkeys in each group, PET studies using a different radiotracer in humans (Volkow et al., 1993) and monkeys (Nader et al., 2006) suggest that duration of exposure is more critical to receptor changes than daily dose or cumulative intake, although numerous neurobiological alterations have been reported in animals following either acute high dose or repeated administration of lower doses of MDMA across a range of contingent or noncontingent dosing parameters (e.g. Ali et al., 1993; O'Shea et al., 1998; Schenk et al., 2007; Banks et al., 2008).

Our assessment of SERT availability at 24 hours following last exposure was chosen in the current study to provide insight for pharmacotherapeutic development. A critical period during abstinence is thought to be the first few days when craving/withdrawal peak and often result in relapse (see O'Brien 2008), although it is noted that craving has not been reported to escalate during the first 24 hours following MDMA use (Hopper et al., 2006), possibly a reflection of the recreational vs compulsive use profile. Li et al. (2010) examined SERT availability prior to non-contingent MDMA administration (4 days, twice daily injections) and at various time points between days 1 and 28 post MDMA administration. SERT availability was reduced by nearly $50 \%$ on day 1 post administration across subcortical and cortical structures that persisted through day 28 post MDMA administration. Scheffel et al. (1998) showed $\sim 50-90 \%$ reductions in SERT binding in baboons beginning on day 13 of MDMA abstinence (same dosing regimen) that persisted through day 40. Further examination showed some recovery of SERT in subcortical areas but sustained reductions in cortical regions 9 and 13 months following MDMA administration. Thus, the effects we observed are most likely related to chronic MDMA self-administration and not a consequence of total intake on the preceding session.

The present data support the hypothesis that distinct cognitive domains may be differentially affected by cocaine versus MDMA self-administration. Rodent (e.g., Harvey et al., 2009), monkey (e.g. Diaz et al., 1996a, b, 1997) and human (e.g., Hester and Garavan, 2004; Colzato et al., 2009) studies have shown that cognitive domains primarily controlled by prefrontal cortical areas are affected by cocaine exposure whereas MDMA use may preferentially affect domains requiring recruitment of numerous cortical brain areas (Browne et al., 2010; for review, see Fernando-Serrano et al., 2010). It is striking that cocaine users showed hypoactivation in the ACC as well as other cortical regions and impaired performance on a Go/NoGo task measuring response inhibition (Kaufmann et al., 2003) while recreational MDMA users showed hyperactivity in a number of cortical regions and no impairments on the same version of the task (Roberts and Garavan, 2010) compared to drug-naïve control groups. While a direct association between SERT availability and cognitive performance cannot be made from the present study, data showing lower SERT availability in monkeys with a history of MDMA self-administration compared to drug- 
naïve and cocaine-exposed monkeys across cortical structures associated with visuospatial planning and memory adds to previous literature that has shown an association of reduced SERT availability and memory impairments (McCann et al., 2008; Kish et al., 2010; Schenk et al., 2010).

Distinct neurobiological consequences of MDMA versus cocaine self-administration substantiate the examination of stimulant-specific treatment strategies. MDMA exposure is associated with reduced SERT in rats, monkeys and humans (Buchert et al., 2003, 2004, 2006, 2007; McCann et al., 1998, 2005, 2008; Kish et al., 2010; Biezonski and Meyer, 2010; Li et al., 2010; present study) but not DAT availability in monkeys (Fantegrossi et al., 2009) or humans (McCann et al., 2008). In contrast, cocaine exposure is associated with elevated SERT availability (Mash et al., 2000; Banks et al., 2008; present study) and DAT binding in monkeys (Letchworth et al., 2001) and humans (Little et al., 1993). Consistent with these mechanisms, Fantegrossi and colleagues (2004) did not see differences in 5-HT neurochemical markers in rhesus monkeys following co-administration of cocaine and MDMA compared to controls, possibly a consequence of their opposing effects on SERT availability. Polydrug use may account for the reported recovery of SERT availability in humans (Buchert et al., 2006) or equivocal effects following MDMA abstinence (Selvaraj et al., 2009). Future studies will be needed to evaluate the efficacy of stimulant-specific treatment strategies to reverse the respective effects of MDMA or cocaine abuse during periods of abstinence and the effects of these treatments on cognitive performance.

\section{Acknowledgments}

This research was supported by National Institute on Drug Abuse grants DA-06634, DA-10584, DA-14637, DA-025120, and DA-020281. The authors wish to acknowledge the technical assistance of Jennifer Martelle, Susan Nader, Kimberly Black, and Jessica Stukes and Pradeep Garg and Sudha Garg for [ ${ }^{11}$ C]DASB synthesis.

\section{References}

Ali SF, Newport GD, Scallet AC, Binienda Z, Ferguson SA, Bailey JR, Paule MG, Slikker W. Oral administration of 3,4-Methylenedioxymethamphetamine (MDMA) produces selective serotonergic depletion in the nonhuman primate. Neurotoxicol Teratol. 1993; 15:91-96. [PubMed: 7685472]

Banks ML, Czoty PW, Gage HD, Bounds MC, Garg PK, Garg S, Nader MA. Effects of cocaine and MDMA self-administration on serotonin transporter availability in monkeys. Neuropsychopharmacology. 2008; 33:219-225. [PubMed: 17443127]

Battaglia G, Brooks BP, Kulsakdinun C, De Souza EB. Pharmacologic profile of MDMA (3,4methylendioxymethamphetamine) at various brain recognition sites. Eur J Pharmacol. 1988; 149:159-163. [PubMed: 2899513]

Battaglia G, Sharkey J, Kuhar MJ, De Souza EB. Neuroanatomic specificity and time course of alterations in rat brain serotonergic pathways induced by MDMA $(3,4-$ methylenedioxymethamphetamine): assessment using quantitative autoradiography. Synapse. 1991; 8:249-260. [PubMed: 1681594]

Battaglia G, Yeh SY, O’Hearn E, Molliver ME, Kuhar MJ, DeSouza EB. 3,4Methylendioxymethamphetamine and 3,4-methylendioxyamphetamine destroy serotonin terminals in rat brain: quantification of neurodegeneration by measurement of $\left[{ }^{3} \mathrm{H}\right]$-paroxetine-labelled serotonin uptake sites. J Pharmacol Exp Ther. 1987; 242:911-916. [PubMed: 2443644]

Bennett BA, Wichems CH, Hollingsworth CK, Davies HM, Thornley C, Sexton T, et al. Novel 2substituted cocaine analogs: uptake and ligand binding studies of dopamine, serotonin, and norepinephrine transport sites in the rat brain. J Pharmacol Exp Ther. 1995; 272:1176-1186. [PubMed: 7891330]

Beveridge TJ, Gill KE, Hanlon CA, Porrino LJ. Review. Parrallel studies of cocaine-related neural and cognitive impairments in humans and monkeys. Philos Trans R Soc Lond B Biol Sci. 2008; 363:3257-66. [PubMed: 18640916] 
Biezonski DK, Meyer JS. Effects of 3,4,-methylenedioxymethamphetamine (MDMA) on serotonin transporter and vesicular monoamine transporter 2 protein and gene expression in rats: implications for MDMA neurotoxicity. J Neurochem. 2010; 112:951-62. [PubMed: 20002520]

Browne J, McKone E, Ward J. Deficits of long-term memory in ecstasy users are related to cognitive complexity of the task. Psychopharmacology. 2010; 209:51-67. [PubMed: 20119830]

Buchert R, Thiele F, Thomasius R, Wilke F, Petersen K, Brenner W, Mester J, Spies L, Clausen M. Ecstasy-induced reduction of the availability of the brain serotonin transporter as revealed by [11C](+)McN5652-PET and the multi-linear reference tissue model: loss of transporters or artifact of tracer kinetic modelling? J Psychopharm. 2007; 21:628-634.

Buchert R, Thomasius R, Nebeling B, Petersen K, Obrocki J, Jenicke L, Wilke F, Wartberg L, Zapletalova P, Clausen M. Long-term effects of "Ecstasy" use on serotonin transporters of the brain investigated by PET. J Nucl Med. 2003; 44:375-384. [PubMed: 12621003]

Buchert R, Thomasius R, Petersen K, Wilke F, Obrocki J, Nebeling B, Wartberg L, Zapletalova P, Clausen M. Reversibility of ecstasy-induced reductions in serotonin transporter availability in polydrug ecstasy users. Eur J Nucl Med Mol Imaging. 2006; 33:188-199. [PubMed: 16133393]

Buchert R, Thomasius R, Wilke F, Petersen K, Nebeling B, Obrocki J, Schulze O, Schmidt U, Clausen M. A voxel-based PET investigation of the long-term effects of "Ecstasy" consumption on brain serotonin transporters. Am J Psychiatry. 2004; 161:1181-1189. [PubMed: 15229049]

Colzato L, Huizinga M, Hommel B. Recreational cocaine polydrug use impairs cognitive flexibility but not working memory. Psychopharmacology. 2009; 207:225-234. [PubMed: 19727676]

Cunningham KA, Paris JM, Goeders NE. Chronic cocaine enhances serotonin autoregulation and serotonin uptake binding. Synapse. 1992; 11:112-123. [PubMed: 1385662]

Everitt BJ, Robbins TW. Neural systems of reinforcement for drug addiction: from actions to habits to compulsion. Nat Neurosci. 2005; 8:1481-1489. [PubMed: 16251991]

Elfving B, Madsen J, Knudsen GM. Neuroimaging of the serotonin reuptake site requires high-affinity ligands. Synapse. 2007; 61:882-888. [PubMed: 17657807]

Ersche KD, Rosier JP, Robbins TW, Sahakian BJ. Chronic cocaine but not chronic amphetamine use is associated with perseverative responding in humans. Psychopharmacology. 2008; 197:421-431. [PubMed: 18214445]

Fantegrossi WE, Bauzo RM, Manvich DM, Morales JC, Votaw JR, Goodman MM, Howell LL. Role of the dopamine transporters in the behavioral effects of 3,4-methylenedioxymethamphetamine (MDMA) in nonhuman primates. Psychopharmacology. 2009; 205:337-47. [PubMed: 19421742]

Fantegrossi WE, Woolverton WL, Kilbourn M, Sherman P, Yuan J, Hatzidimitriou G, Ricaurte GA, Woods JH, Winger G. Behavioral and neurochemical consequences of long-term intravenous selfadministration of MDMA and its enantiomers by rhesus monkeys. Neuropsychopharmacology. 2004; 29:1270-1281. [PubMed: 15039771]

Fernandez-Serrano MJ, Perez-Garcia M, Verdejo-Garcia A. What are the specific vs generalized effects of drugs of abuse on neuropsychological performance? Neurosci Biobehav Rev. 201010.1016/j.neubiorev.2010.04.008

Fillmore MT, Rush CR. Impaired inhibitory control of behavior in chronic cocaine users. Drug Alcohol Depen. 2002; 66:265-273.

Fillmore MT, Rush CR, Hays L. Cocaine improves inhibitory control in human model of response conflict. Exp Clin Psychopharmacol. 2005; 13:327-335. [PubMed: 16366763]

Fillmore MT, Rush CR, Hays L. Acute effects of cocaine in two models of inhibitory control: implications of non-linear dose effects. Addiction. 2006; 101:1323-1332. [PubMed: 16911732]

Goldstein RZ, Volkow ND. Drug addiction and its underlying neurobiological basis: Neuroimaging evidence for the involvement of the frontal cortex. Am J Psychiatry. 2002; 159:1642-1652. [PubMed: 12359667]

Goldstein RZ, Tomasi D, Rajaram S, Cottone LA, Zhang L, Maloney T, et al. Role of the anterior cingulate and medial orbitofrontal cortex in processing drug cues in cocaine addiction. Neuroscience. 2007; 144:1153-1159. [PubMed: 17197102]

Green AR, Mechan AO, Elliott JM, O'Shea E, Colado MI. The pharmacology and clinical pharmacology of 3,4-methylenedioxymethamphetamine (MDMA, "ecstasy"). Pharmacol Rev. 2003; 55:463-508. [PubMed: 12869661] 
Gudelsky GA, Yamamoto BK. Actions of 3,4-methylendioxymethamphetamine (MDMA) on cerebral dopaminergic, serotonergic, and cholinergic neurons. Pharmacol Biochem Behav. 2008; 90:198207. [PubMed: 18035407]

Harvey RC, Dembro KA, Rajagopalan K, Mutebi MM, Kantak KM. Effects of self-administered cocaine in adolescent and adult male rats on orbitofrontal cortex-related neurocognitive functioning. Psychopharmacology. 2009; 206:61-71. [PubMed: 19513699]

Hester R, Garavan H. Executive dysfunction in cocaine addiction: Evidence for discordant frontal, cingulate, and cerebellar activity. J Neurosci. 2004; 24:11017-11022. [PubMed: 15590917]

Hopper JW, Su Z, Looby AR, Ryan ET, Penetar DM, Palmer CM, Lukas SE. Incidence and patterns of polydrug use and craving for ecstasy in regular ecstasy users: An ecological momentary assessment study. Drug and Alcohol Depend. 2006; 85:221-235.

Insel TR, Battaglia G, Johannessen JN, Marra S, De Souza EB. 3,4-Methylenedioxymethamphetamine ("ecstasy") selectively destroys brain serotonin terminals in rhesus monkeys. J Pharmacol Exp Ther. 1989; 249:713-720. [PubMed: 2471824]

Jacobsen LK, Staley JK, Malison RT, Zoghbi SS, Seibyl JP, Kosten TR, Innis RB. Elevated central serotonin transporter binding availability in acutely abstinent cocaine-dependent patients. Am J Psychiatry. 2000; 157:1134-1140. [PubMed: 10873923]

Kaufman JN, Ross TJ, Stein EA, Garavan H. Cingulate hypoactivity in cocaine users during a GONOGO task as revealed be event-related functional magnetic resonance imaging. J Neurosci. 2003; 23:7839-7843. [PubMed: 12944513]

Kish SJ, Lerch J, Furukawa Y, Tong J, McCluskey T, Wilkins D, Houle S, Meyer J, Mundo E, Wilson AA, Rusjan PM, Saint-Cyr JA, Guttman M, Collins DL, Shapiro C, Warsh JJ, Boileau I. Decreased cerebral cortical serotonin transporter binding in ecstasy users: a positron emission tomography/[(11)C]DASB and structural brain imaging study. Brain. 2010; 133:1779-1797. [PubMed: 20483717]

Kittler K, Lau T, Schloss P. Antagonists and substrates differentially regulate serotonin transporter cell surface expression in serotonergic neurons. Eur J Pharmacol. 2010; 629:63-67. [PubMed: 20006597]

Kivell B, Day D, Bosch P, Schenk S, Miller J. MDMA causes a redistribution of serotonin transporter from the cell surface to the intracellular compartment by a mechanism independent of phosphoP38-mitogen activated protein kinase activation. Neuroscience. 2010; 168:82-95. [PubMed: 20298763]

Kubler A, Murphy K, Garavan H. Cocaine dependence and attention switching within and between verbal and visuospatial working memory. Eur J Neurosci. 2005; 21:1984-1992. [PubMed: 15869491]

Letchworth SR, Nader MA, Smith HR, Friedman DP, Porrino LJ. Progression of changes in dopamine transporter binding site density as a result of cocaine self-adminstration in rhesus monkeys. $\mathbf{J}$ Neurosci. 2001; 21:2799-2807. [PubMed: 11306632]

Li IH, Huang WS, Shiue CY, Huang YY, Liu RS, Chyeuh SC, et al. Study on the neuroprotective effect of fluoxetine against MDMA-induced neurotoxicity on the serotonin transporter in rat brain using micro-PET. NeuroImage. 2010; 49:1259-1270. [PubMed: 19682588]

Lile JA, Ross JT, Nader MA. A comparison of the reinforcing efficacy of 3,4methylenedioxymethamphetamine (MDMA, "ecstasy") with cocaine in rhesus monkeys. Drug and Alcohol Depend. 2005; 78:135-140.

Little KY, Kirkman JA, Carroll FI, Clark TB, Duncan GE. Cocaine use increases $\left[{ }^{3} \mathrm{H}\right]$ WIN 35428 binding sites in human striatum. Brain Res. 1993; 628:17-25. [PubMed: 8313144]

Liu S, Heitz RP, Sampson AR, Zhang W, Bradberry CW. Evidence of temporal cortical dysfunction in rhesus monkeys following chronic cocaine self-administration. Cerebral Cortex. 2008; 18:2109_ 2116. [PubMed: 18096561]

Logan J, Fowler JS, Wolkow ND, Wang GJ, Ding YS, Alexoff DL. Distribution volume ratios without blood sampling from graphical analysis of PET data. J Cereb Blood Flow Metab. 1996; 16:834840. [PubMed: 8784228]

Mash DC, Staley JK, Izenwasser S, Basile M, Ruttenber AJ. Serotonin transporters upregulate with chronic cocaine use. J Chem Neuroanat. 2000; 20:271-280. [PubMed: 11207425] 
McCann UD, Szabo Z, Scheffel U, Dannals RF, Ricaurte GA. Positron emission tomographic evidence of toxic effect of MDMA ("Ecstasy") on brain serotonin neurons in human beings. Lancet. 1998; 352:1433-1437. [PubMed: 9807990]

McCann UD, Szabo Z, Seckin E, Rosenblatt P, Mathews WB, Ravert HT, Dannals RF, Ricaurte GA. Quantitative PET studies of the serotonin transporter in MDMA users and controls using $\left[{ }^{11} \mathrm{C}\right] \mathrm{McN} 5652$ and $\left[{ }^{11} \mathrm{C}\right] \mathrm{DASB}$. Neuropsychopharmacology. 2005; 30:1741-1750. [PubMed: 15841106]

McCann UD, Szabo Z, Vranesic M, Palermo M, Mathews WB, Ravert HT, Dannals RF, Ricaurte GA. Positron emission tomographic studies of brain dopamine and serotonin transporters in abstinent ( \pm 3,4-methlenedioxymethamphetamine ("ecstasy") users: relationship to cognitive performance. Psychopharmacology. 2008; 200:439-450. [PubMed: 18661256]

Nader MA, Morgan D, Gage HD, Nader SH, Calhoun TL, Buchheimer N, Ehrenkaufer R, Mach RH. PET imaging of dopamine $\mathrm{D} 2$ receptors during chronic cocaine self-adminstration in monkeys. Nat Neurosci. 2006; 9:1050-6. [PubMed: 16829955]

O’Brien CP. Evidence-based treatments of addiction. Philos Trans R Soc Lond B Biol Sci. 2008; 363:3277-3286. [PubMed: 18640914]

O'Shea E, Granados R, Esteban B, Colado MI, Green AR. The relationship between the degree of neurodegeneration of rat brain 5-HT nerve terminals and the dose and frequency of administration of MDMA ('ecstasy'). Neuropharmacology. 1998; 37:919-926. [PubMed: 9776387]

Roberts GMP, Garavan H. Evidence of increased activation underlying cognitive control in ecstasy and cannabis users. Neuroimage. 2010; 52:429-435. [PubMed: 20417713]

Sarkar S, Schmued L. Neurotoxicity of Ecstasy (MDMA): An overview. Curr Pharm Biotechnol. 2010; 11:460-469. [PubMed: 20420572]

Scheffel U, Szabo Z, Mathews WB, Finley PA, Dannals RF, Ravert HT, Szabo K, Yuan J, Ricaurte GA. In vivo detection of short- and long-term MDMA neurotoxicity- A positron emission tomography study in the living baboon brain. Synapse. 1998; 29:183-192. [PubMed: 9593108]

Schenk S. MDMA self-administration in laboratory animals: a summary of the literature and proposal for future research. Neuropsychobiology. 2009; 60:130-136. [PubMed: 19893330]

Schenk, S.; Harper, DN.; Do, J. Novel object recognition memory: measurement issues and effects of MDMA self-administration following short inter-trial intervals. J Psychopharmacol. 2010. in press(online at http://jop.sagepub.com/content/early/2010/12/02/0269881110389213)

Schenk S, Hely L, Lake B, Daniela E, Gittings D, Mash DC. MDMA self-administration in rats: acquisition, progressive ratio responding and serotonin transporter binding. Eur J Neurosci. 2007; 26:3229-3236. [PubMed: 18005064]

Selvaraj S, Hoshi R, Bhagwagar Z, Murthy NV, Hinz R, Cowen P, Curran HV, Grasby P. Brain serotonin transporter binding in former users of MDMA ('ecstasy'). British Journal Psychiatry. 2009; 194:355-359.

Sprague JE, Everman SL, Nichols DE. An integrated hypothesis for the serotonergic axonal loss induced by 3,4,-methylenedioxymethamphetamine. Neurotoxicology. 1998; 19:427-431. [PubMed: 9621349]

Steele TD, Nichols DE, Yim GK. Stereochemical effects of 3,4, methylenedioxymethamphetamine (MDMA) and related amphetamine derivatives on inhibition of uptake of $\left[{ }^{3} \mathrm{H}\right]$ monoamines into synaptosomes from different regions of rat brain. Biochem Pharmacol. 1987; 36:2297-2303. [PubMed: 2886126]

Szabo Z, McCann UD, Wilson AA, Scheffel U, Owonikoko T, Mathews WB, et al. Comparison of $(+)-{ }^{11} \mathrm{C}-\mathrm{McN} 5652$ and ${ }^{11} \mathrm{C}-\mathrm{DASB}$ as serotonin transporter radioligands under various experimental conditions. J Nucl Med. 2002; 43:678-692. [PubMed: 11994534]

Turner TH, LaRowe S, Horner MD, Herron J, Malcolm R. Measures of cognitive functioning as predictors of treatment outcome for cocaine dependence. J Substance Abuse Treatment. 2009; 37:328-334.

Verrico CD, Lynch L, Fahey MA, Fryer AK, Miller GM, Madras BK. MDMA-induced impairment in primates: antagonism by a selective norepinephrine or serotonin, but not by a dopamine/ norepinephrine transport inhibitor. J Psychopharmacology. 2008; 22:187-202. 
Vogt BA. Pain and emotion interactions in subregions of the cingulate gyrus. Nat Rev Neurosci. 2005; 6:533-544. [PubMed: 15995724]

Volkow ND, Fowler JS, Wang G-J, Hitzemann R, Logan J, Schyler DJ, Dewey SL, Wolf AP. Decreased dopamine $\mathrm{D}_{2}$ receptor availability is associated with reduced frontal metabolism in cocaine abusers. Synapse. 1993; 14:169-177. [PubMed: 8101394]

Vollenweider FX, Gamma A, Liechti M, Huber T. Psychological and cardiovascular effects and shortterm sequelae of MDMA ("ecstasy") in MDMA-naive healthy volunteers. Neuropsychopharmacology. 1998; 19:241-251. [PubMed: 9718588]

Yu C, Zhou Y, Liu Y, Jiang T, Dong H, Zhang Y, Walter M. Functional segregation of the human cingulate cortex is confirmed by functional connectivity based neuroanatomical parcellation. Neuroimage. 2010 epub ahead of print; 10.1016/j.neuroimage.2010.11.018 


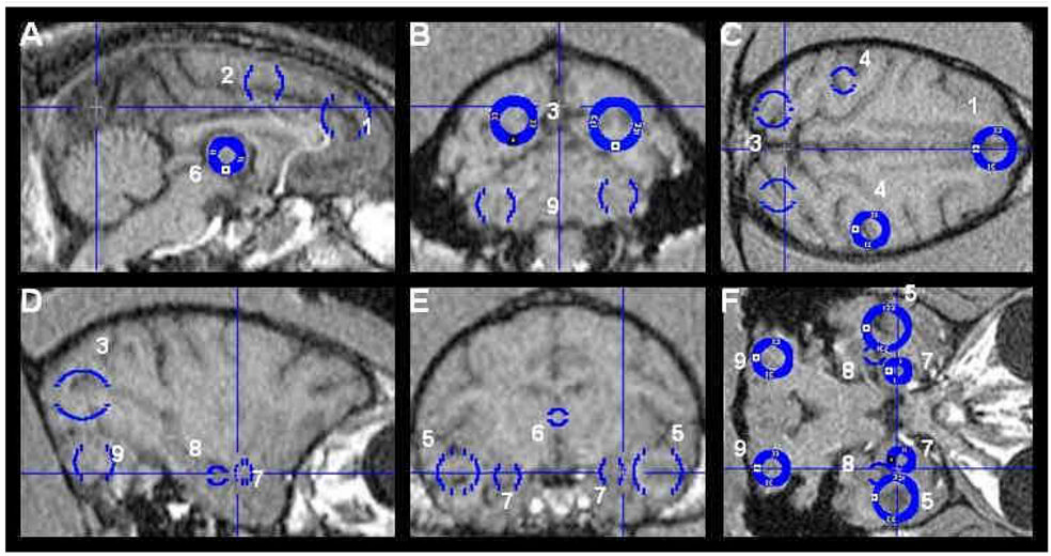

Figure 1.

Anatomical locations for regions of interest (ROIs); 1) prefrontal cortex; 2) midcingulate cortex; 3) bilateral occipital cortices; 4) bilateral parietal cortices; 5) bilateral temporal cortices; 6) thalamus; 7) bilateral amygdala; 8) bilateral hippocampi; 9) bilateral cerebellum represented in saggital $(\mathrm{A}, \mathrm{D})$, coronal $(\mathrm{B}, \mathrm{E})$, and horizontal $(\mathrm{C}, \mathrm{F})$ planes. 


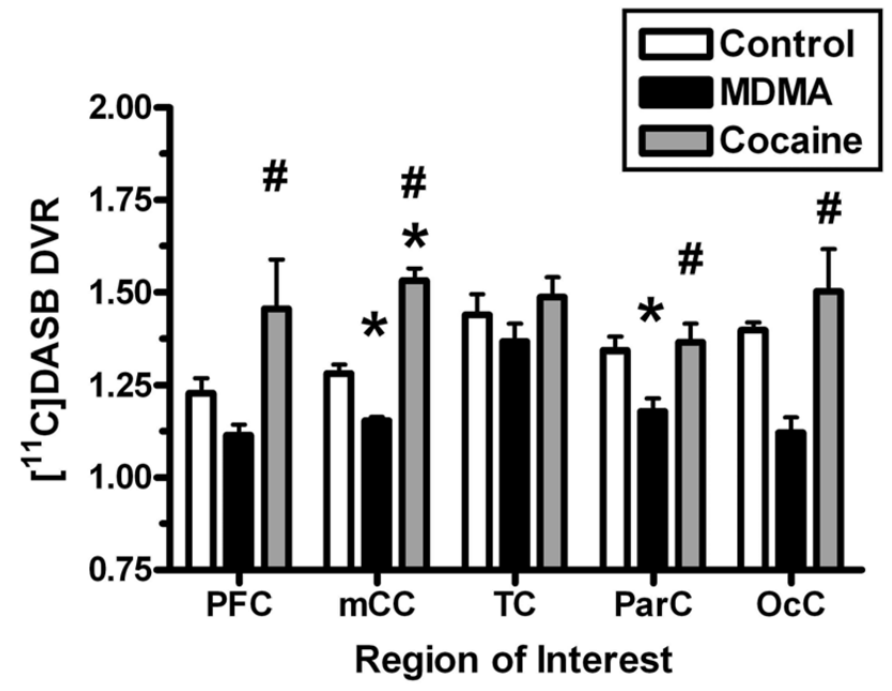

Figure 2.

SERT availability expressed as distribution volume ratios (DVRs) in monkeys with a history of MDMA or cocaine self-administration and drug-naïve control monkeys. Bars represent group mean $( \pm \mathrm{SEM})$; PFC, prefrontal cortex; mCC, midcingulate cortex; TC, temporal cortex; ParC, parietal cortex; OcC, occipital cortex. * denotes significantly different from control $(\mathrm{p}<0.05)$; \#, significantly different from MDMA group $(\mathrm{p}<0.05)$. 


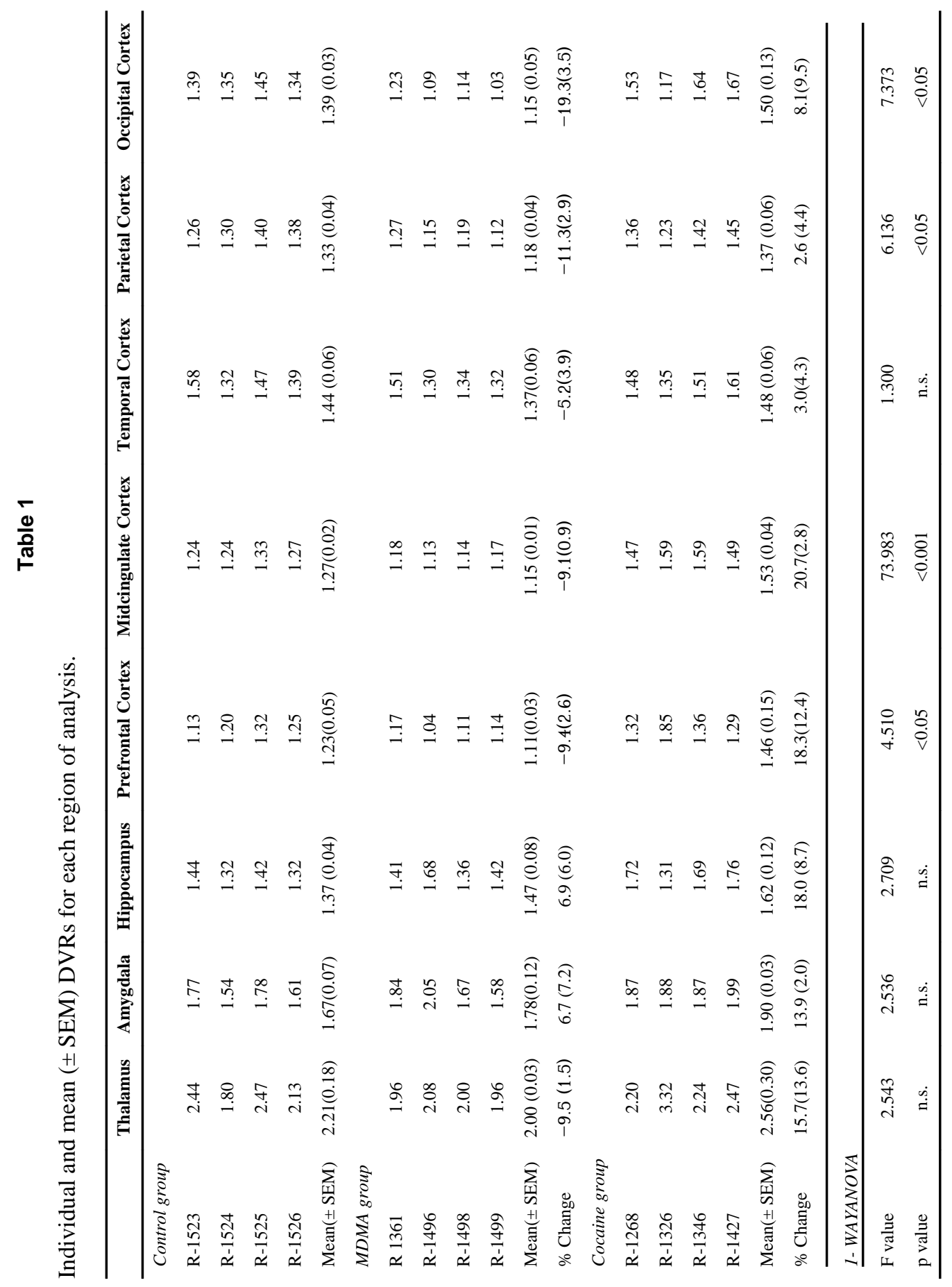

